\title{
Bacteroides fragilis Supernatant Extracts Enriched in Phenylacetic Acid Induce a Cytotoxic Effect in Mammalian Cells
}

\author{
Laís S. Falcão ${ }^{1,2}$, Eduardo N. F. Antunes², Eliane 0. Ferreira ${ }^{2}$, Heidi Pauer ${ }^{2}$, \\ Maria Teresa V. Romanos ${ }^{2}$, Rossiane C. Vommaro ${ }^{3}$, Sérgio H. Seabra ${ }^{3,4}$, \\ Daniela S. Alviano², Celuta S. Alviano², Antonio Jorge R. da Silva ${ }^{5}$, \\ Leandro A. Lobo ${ }^{2 *}$, Regina Maria C. P. Domingues²
}

${ }^{1}$ Departamento de Ciências Básicas, Pólo Universitário de Nova Friburgo, Universidade Federal Fluminense, Nova Friburgo, Brasil

${ }^{2}$ Instituto de Microbiologia Prof. Paulo de Góes, Universidade Federal do Rio de Janeiro, Rio de Janeiro, Brasil

${ }^{3}$ Instituto de Biofísica Carlos Chagas Filho, Universidade Federal do Rio de Janeiro, Rio de Janeiro, Brasil

${ }^{4}$ Centro Universitário Estadual da Zona Oeste-UEZO, Rio de Janeiro, Brasil

${ }^{5}$ Instituto de Pesquisa Produtos Naturais, Universidade Federal do Rio de Janeiro, Rio de Janeiro, Brasil

Email: ${ }^{\text {lobol@micro.ufri.br }}$

Received 15 August 2015; accepted 27 September 2015; published 30 September 2015

Copyright (C) 2015 by authors and Scientific Research Publishing Inc.

This work is licensed under the Creative Commons Attribution International License (CC BY).

http://creativecommons.org/licenses/by/4.0/

(c) (i) Open Access

\section{Abstract}

Bacteroides species are nearly half of the fecal flora community and some are host symbionts crucial to host nutrition and systemic immunity. Among Bacteroides species B. fragilis strains are considered to be the opportunistic ones, being the most isolated anaerobic bacteria in clinical samples. Cell-free supernatants of 65 B. fragilis strains were assayed and they were capable of inducing vacuolating phenotype on Vero cells lineage. The supernatant of the Bacteroides fragilis ATCC 23745 strain was elicited to have the strongest vacuolating effect on Vero cells monolayers and peritoneal macrophages. Some drastic cell alterations were observed, such as a general disorganization of cytoplasm and chromatin condensation, evidencing cell death. By transmission electron microscopy it was confirmed that the vacuoles observed were, in fact, swollen mitochondria. An immunocytochemical assay, TUNEL, was used to confirm this hypothesis and showed that Vero cells and peritoneal macrophages were dying by apoptotic process after exposition of $B$. fragilis cell-free supernatant. Physical analysis of the apoptotic factor has revealed properties similar to short-chain fatty acids. After gas chromatography and mass spectrometry analysis, phenylacetic acid (PA) was characterized as the major compound present in the most purified active fraction. We believe that the PA is responsible for the pro-apoptotic effect elicited by the supernatant of $B$. fragilis cultures.

\footnotetext{
"Corresponding author.

How to cite this paper: Falcão, L.S., Antunes, E.N.F., Ferreira, E.O., Pauer, H., Romanos, M.T.V., Vommaro, R.C., Seabra, S.H., Alviano, D.S., Alviano, C.S., da Silva, A.J.R., Lobo, L.A. and Domingues, R.M.C.P. (2015) Bacteroides fragilis Supernatant Extracts Enriched in Phenylacetic Acid Induce a Cytotoxic Effect in Mammalian Cells. Advances in Microbiology, 5, 730-736. http://dx.doi.org/10.4236/aim.2015.510077
} 


\section{Keywords}

\section{Bacteroides fragilis, Vacuolization, Apoptosis, Vero cells Lineage, Peritoneal Macrophages, Phenylacetic Acid}

\section{Introduction}

The intestinal microbiota is the largest bacterial reservoir in humans and it is mainly composed by anaerobic bacteria, especially from the genera Bacteroides and Bifidobacterium that are considered the most prevalent. A recent report has suggested that there are at least 1800 genera and 15,000 - 36,000 species of bacteria in the human gastrointestinal tract [1]. This microbiota is responsible for several beneficial processes, for instance degradation of complex polysaccharides and protection of the gut epithelia from colonization by pathogenic bacteria [2]. This symbiotic relationship is not always positive and when the intestinal wall barrier is breached and luminal contents escape into the peritoneal cavity, opportunistic pathogens may emerge and become a threat.

Although Bacteroides fragilis is a minor component of this niche, it is the anaerobic bacteria most frequently isolated from clinical infections, such as intra-abdominal processes and bacteraemias. Many virulence factors have been described for this microorganism, including the expression of a capsular polysaccharide complex, know as CPC, adhesins and hydrolytic enzymes [3]. Some $B$. fragilis strains can also produce an enterotoxin (B. fragilis toxin-BFT) associated with acute diarrheal disease; these strains are referred as $B$. fragilis enterotoxigenic (ETBF) [4].

As already mentioned, anaerobic bacteria, including Bacteroides species, are normally more abundant than facultative bacteria in the gastrointestinal tract, where they produce a large amount of different organic acids [5]. Several studies have reported cytotoxic effects elicited by culture filtrates of anaerobic bacteria. In some of these investigations, it was revealed that this phenomenon was associated with short-chain fatty acids (SCFA) production [6] [7]. In a study developed in 1985 by Grenier \& Mayrand, and more recently by Ohkusa and colleagues in 2003 [8] [9], it could be observed that SCFA production by Porphyromonas gingivalis and Fusobacterium varium was associated with a cytotoxic activity against different mammalian cells, such as Vero and Caco-2 cell lineage.

During its metabolism, $B$. fragilis along with other species of the genus produces large amounts of SCFA derived from the fermentation of complex polyssacharides. Here we compared the supernatants of B. fragilis cultures isolated from infectious processes and microbiota in their ability to induce alterations on mammalian Vero cells. We performed cytological and chemical characterization of the supernatants to determine which component presented in the supernatant was responsible for the alteration observed in mammalian cells.

\section{Material \& Methods}

\subsection{Bacterial Strains and Growing Conditions}

Eigtheen $B$. fragilis strains isolated from intestinal microbiota and fourty-two from intra-abdominal infections were selected in order to analyze the effect of their cell-free supernatants on Vero cells. These strains were previously characterized as nontoxigenic, meaning they do not contain the $b f t$ gene [10]. Besides that, two ETBF strains 078320 and 079298-3 and three collection type strains obtained from the American Type Culture Collection were used (ATCC 23745, ATCC 25285 and ATCC 043859). Prior to experiments, all strains were grown in Brain Heart Infusion-pre-reduced anaerobically sterilized (BHI-PRAS) medium supplemented with hemin and L-cysteine for $24 \mathrm{~h}$ at $37^{\circ} \mathrm{C}$ in anaerobiosis [11].

\subsection{Cell Culture}

Vero cells were grown in $25 \mathrm{~cm}^{3}$ flasks with $4 \mathrm{ml}$ of Dulbecco's Modified Eagle Medium (D-MEM), supplemented with 10\% (v/v) fetal bovine serum (FBS), L-glutamine (5 ml/l), Fungizone (25 ml/l), Gentamicin (50 $\mu \mathrm{g} / \mathrm{ml}$ ) and incubated in a 5\% $\mathrm{CO}_{2}$ BOD (Biochemical Oxygen Demand). For the experiments, approximately $2.2 \times 10^{5}$ cells were plated onto 24 well cell culture plates with cover slips and maintained in a $5 \% \mathrm{CO}_{2}$ BOD for $24 \mathrm{~h}$ at $37^{\circ} \mathrm{C}$. 
Macrophages were obtained after intra-peritoneal inoculation of $30 \mathrm{mg} / \mathrm{ml}$ thioglycolate medium in male mice. After $72 \mathrm{~h}$, peritoneal cells were collected aseptically by peritoneal lavage with ice-cold D-MEM and centrifuged at $600 \times \mathrm{g}$ for $10 \mathrm{~min}$ at $4^{\circ} \mathrm{C}$, suspended in fresh medium, counted and plated in 24 well plates in a concentration of $2.0 \times 10^{6}$ cells/ml. Adherent cells were obtained plating $150 \mu \mathrm{l}$ of the cell suspension onto cover slips previously placed in 24 well cell culture plates. After $1 \mathrm{~h}$ of incubation in a $5 \% \mathrm{CO}_{2} \mathrm{BOD}$ at $37^{\circ} \mathrm{C}$, plates were washed to remove non-adherent cells and fresh medium supplemented with $10 \%$ FBS was added [12].

\subsection{Interaction Assays}

Briefly, the 65 overnight cultures $\left(\mathrm{OD}_{550}=1.1\right)$ were centrifuged at $3.500 \times \mathrm{g}$ for 5 min and supernatants collected and passed through $0.22 \mu \mathrm{m}$ filter membranes (Millipore ${ }^{\circledR}$ ). One milliliter of sterile supernatant was added in each well of the tissue culture plate and after 45, 60, 120 and 180 min of incubation cultures were observed in an Inverted Light Microscopy-ILM (Axiovert 25, Zeiss). All experiments were performed in triplicate and BHI-PRAS and D-MEM were used as negative controls.

Our results showed that ATCC 23745 strain caused the strongest vacuolating effect, so this strain was chosen for further investigations. Vero cells were grown in cell culture flasks for $24 \mathrm{~h}$ in a $5 \% \mathrm{CO}_{2} \mathrm{BOD}$ at $37^{\circ} \mathrm{C}$, washed with PBS and then incubated with $3 \mathrm{ml}$ of the sterile supernatant of the strain ATCC 23745 and intervals were taken at 8, 15, 30, 45, 60, 120 and $180 \mathrm{~min}$. After incubation, the cells were washed three times with $0.01 \mathrm{M}$ PBS (pH 7.4) and fixed in $2.5 \%$ glutaraldeyde with $3 \%$ sucrose in $0.1 \mathrm{M}$ sodium cacodylate buffer, $\mathrm{pH}$ 7.2. Cells were post fixed in a solution containing $1 \% \mathrm{OsO}_{4}, 0.8 \%$ potassium ferrocyanide and $5 \mathrm{mM} \mathrm{CaCl}$, in $0.1 \mathrm{M}$ cacodylate buffer for $1 \mathrm{~h}$ at room temperature in the dark. Dehydration was carried out with graded series of acetone (50\% - 100\%) and embedded in Polybed (Polyscience). Thin sections were made and stained with uranyl acetate and lead citrate. These sections were observed under a Zeiss 900 Transmission Electron Microscope (TEM). All experiments were performed in duplicate and BHI-PRAS and D-MEM media were used as negative controls [13].

\subsection{Interaction with Peritoneal Macrophages}

The supernatant of the ATCC 23745 strain was also incubated with peritoneal macrophages. The cells were washed with PBS (2×) and $1 \mathrm{ml}$ of sterile supernatant was added in each well of the 24 culture plates. After 30 min of interaction, cells were observed under a confocal microscopy system-CMS (MCL-LSM310, Zeiss). All experiments were performed in triplicate and BHI-PRAS was used as negative control.

\subsection{Immunocytochemical Assays}

TUNEL assay (Molecular Probes) were performed to monitor the apoptosis in the Vero cells and peritoneal macrophages assays as proposed by Matsumoto and colleagues 2006 [14].

\subsection{Supernatant Characterization}

The ATCC 23745 supernatant was exposed to temperatures from a range of $50^{\circ} \mathrm{C}$ to $100^{\circ} \mathrm{C}$ during of $5,10,15$ and $30 \mathrm{~min}$. The supernatant also exposed to autoclaving $\left(121^{\circ} \mathrm{C}\right.$ under pressure of $1.5 \mathrm{ATM}$ for $\left.15 \mathrm{~min}\right)$. These supernatants were frozen $\left(-20^{\circ} \mathrm{C}\right)$, and kept at $4^{\circ} \mathrm{C}$ to observe their resistance to extreme temperatures. The crude supernatant was also filtered using Amicon Diaflo (Millipore) membranes with molecular weight cut-off of 10,3 and $1 \mathrm{kDa}$, in order to estimate the molecular mass of the apoptotic factor. Non-treated supernatants were assayed as controls. Analysis was done by ILM, TEM and CMS. The fraction showing apoptotic action was submitted to gas chromatography and mass spectrometry for detection of major compound present.

\section{Results}

All 65 B. fragilis strains supernatants tested were capable of eliciting a vacuolating phenotype on Vero cells monolayers. Nevertheless, some of them delayed in producing vacuoles, particularly the ETBF strains (078320 and 079298-3). The control cells, which were incubated with BHI-PRAS or D-MEM, did not show any changes in the morphology (Figure 1(a)). The type strain ATCC 23745 showed the strongest effect on Vero cells in only 

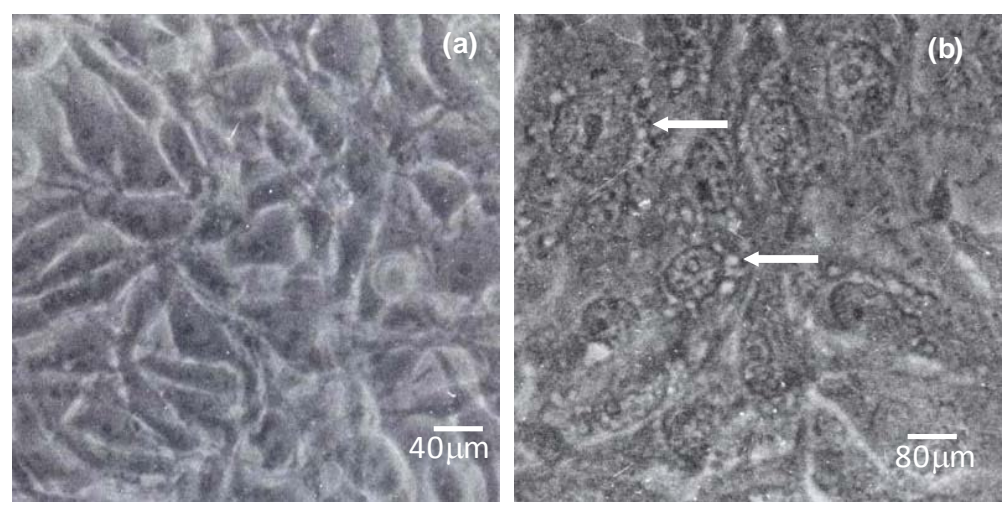

Figure 1. Interaction of the supernatant of the Bacteroides fragilis ATCC 23745 strain with Vero cells monolayers for 60 minutes analyzed by light microscopy. (a) Vero cells incubated with BHI-PRAS. Cells present the characteristic morphology; (b) Vero cells incubated with crude supernatant of the strain ATCC 23745. Note the vacuolated aspect of cells cytoplasm (arrow) and the alteration of nuclear membrane. Bars: (a) $40 \mu \mathrm{m}$ and (b) $80 \mu \mathrm{m}$.

45 min (Figure 1(b)), and no differences were observed in the vacuoles formation between strains isolated from microbiota and infectious processes.

To analyze the effect of the supernatant of ATCC 23745 strain on Vero cells by TEM, different incubation intervals were chosen. After only 8 min of incubation, the Vero cells have already shown a chromatin condensation and cytoplasm disorganization (Figure 2(b)). After $120 \mathrm{~min}$, swollen mitochondria were observed; which probably corresponded to the vacuoles observed in optical microscopy preparations. The cells presented a general cytoplasm disorganization and remarkable irregular condensed chromatin in the nucleus (Figure 2(c)), suggesting a process of apoptosis. The control cells presented typical morphology, as observed in Figure 2(a), including normal chromatin distribution. Peritoneal Macrophages incubated with the ATCC 23745 strain supernatant presented shrinkage of cytoplasm and roundness after $30 \mathrm{~min}$ of incubation (data not shown) while control cells present a characteristic morphology.

In order to evaluate if exposition to bacterial supernatant resulted in DNA fragmentation, the TUNEL staining was performed as a hallmark of apoptosis. Positive reactions were observed with Vero cells (data not shown) and peritoneal macrophages (Figure 3) after incubation of with cell free supernatant after $30 \mathrm{~min}$.

None of the physical treatments (heat and cold) of the supernatant of ATCC 23745 abolished the vacuolating effect observed with intact supernatant. The filtered extracts obtained after passage through membranes with cut-off of 10, 3 and $1 \mathrm{kDa}$, retained activity and the supernatant of containing the smallest molecules $(1 \mathrm{kDa})$ could still induce the drastic alterations observed previously in mammalian cells (Figure 2(c)). Based on gas chromatography and mass spectrometry (Figure 4), phenylacetic acid (PA) was characterized as being the major compound present in the active purified fraction of supernatant.

\section{Discussion}

There are several evidences showing that mitochondria have an essential function in apoptosis, through proapoptotic factors released, such as cytochrome $c$, which is localized within the intermembrane space [15]. In this work, we show a severe alteration caused on mammalian cells by supernatants of an in vitro culture of $B$. fragilis, in which the main modification detected by ILM was the apparent presence of intracellular vacuoles. In depth, analysis of these vacuoles by TEM revealed that these are in fact swollen mitochondria. In addition to that, it observed a severe damage to the cell, with general disorganization of cytoplasm and chromatin condensation, evidences of cell death by apoptosis. As mentioned above, mitochondria could release cytochrome $c$ in the cytoplasm of the cell, activating the apoptosis cascade [16]. This hypothesis was confirmed through TUNEL, an immunocytochemical assay that confirmed a fragmentation of DNA. We used two different lineages of mammalian cells in this study, Vero cells and peritoneal macrophages isolated from mouse. After exposure to cell-free supernatant of $B$. fragilis strains, both have shown a remarkable alteration associated with death cell. Mammalian cells vacuolation, in response to bacterial secreted proteins has been already described for Helicobacter 

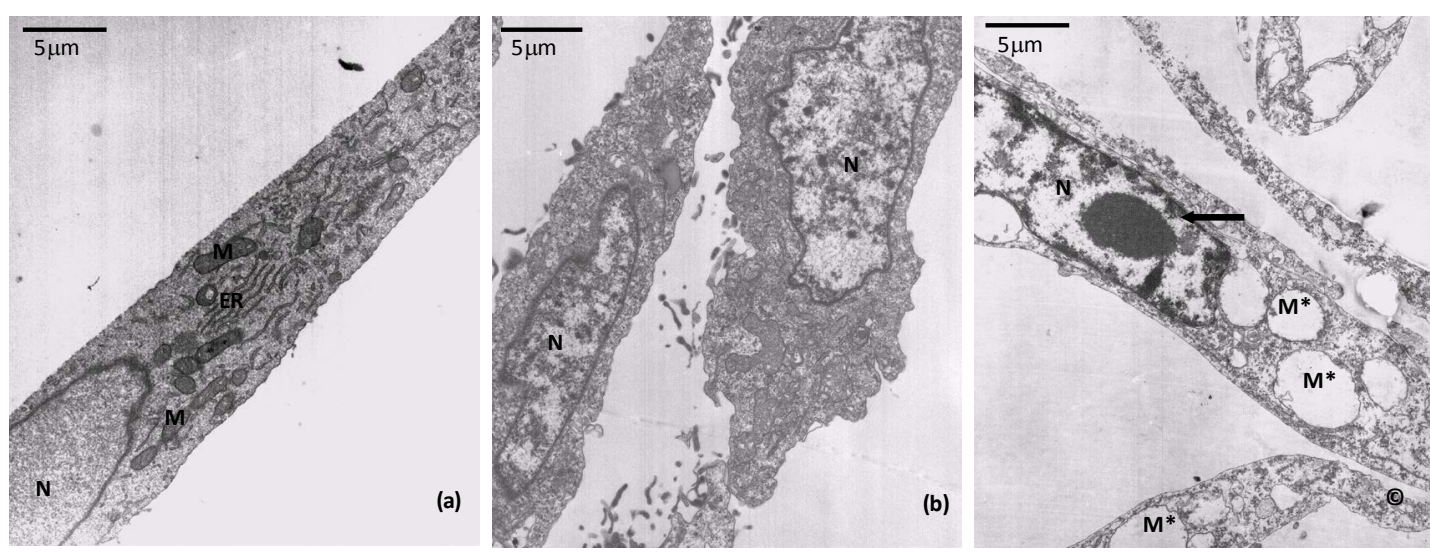

Figure 2. Interaction of the supernatant of the Bacteroides fragilis ATCC 23745 strain with Vero cells monolayer analyzed by transmission electron microscopy. (a) Ultrathin sections of Vero cells incubated with BHI-PRAS. Typical cell structures, such as endoplasmic reticulum profiles (ER), mitochondria (M) and well-preserved membranes can be observed. The nucleus (N) presented a standard chromatin condensation pattern; (b) (c) Effect of ATCC 23745 crude supernatant. In (b), disorganized cytoplasm is apparent after 8 min of interaction. In (c), after 120 min many swelled mitochondria $\left(M^{*}\right)$ can be observed, which correspond to the vacuoles observed in light microscopy preparations. General disorganization of cytoplasm and remarkable irregular condensed chromatin in nucleus $(\mathrm{N})$ suggest of apoptosis cell death (arrow). Bars: $5 \mu \mathrm{m}$.
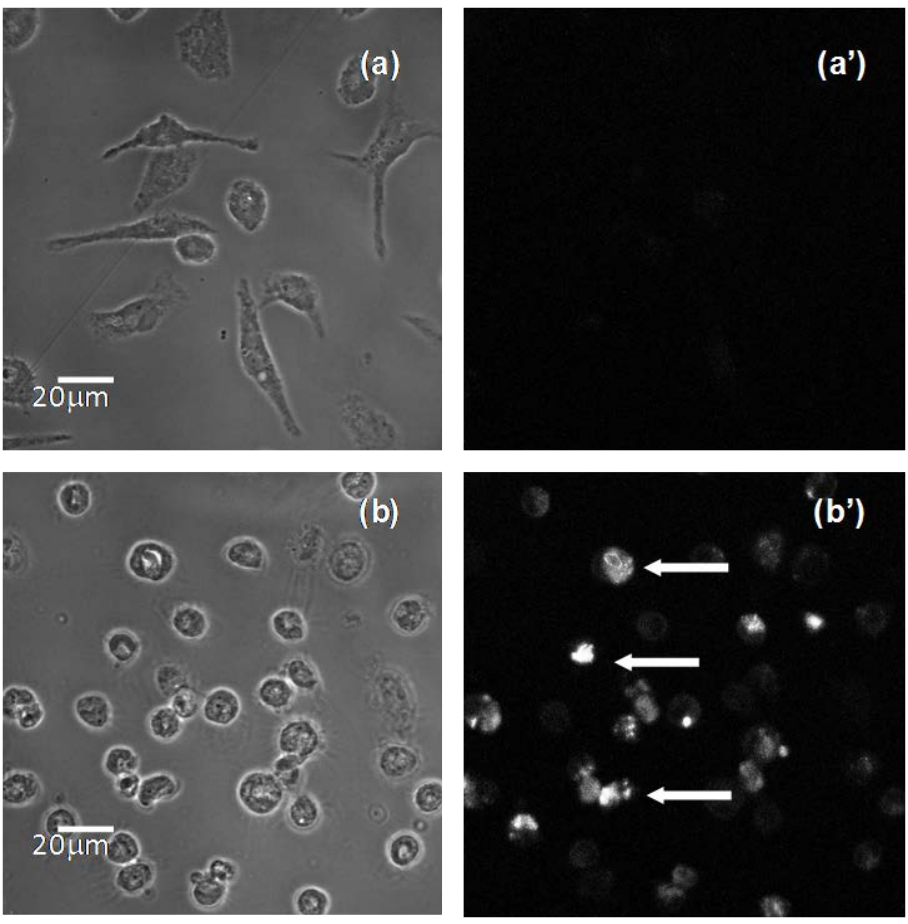

Figure 3. DNA fragmentation of peritoneal macrophages evaluated by TUNEL. (a) shows phase-contrast images of typical spread peritoneal macrophages incubated with BHI-PRAS $30 \mathrm{~min}$; (a') shows the corresponding fluorescence imaging of the same cells incubated with BrdUTP and revealed with anti-BrdU antibody Alexa Fluor ${ }^{\circledR}$ 488 dye; (b) shows phase-contrast images of peritoneal macrophages incubated with the crude supernatant of the strain ATCC 23745 for 30 min, respectively, the cytoplasm shrinkage and round is evident; (b') corresponding fluorescence imaging of the same cells showing nuclear fluorescence (arrows). Bars: $20 \mu \mathrm{m}$.

pylori [17], Bacillus cereus [18] and Vibrio cholerae [19] among other bacterial pathogens. In this work, the apoptotic factor produced by $B$. fragilis maintained the capacity of inducing vacuolation on Vero cells following physical treatments. The molecule has shown a heat-stability, as well a cold resistance incompatible with a 


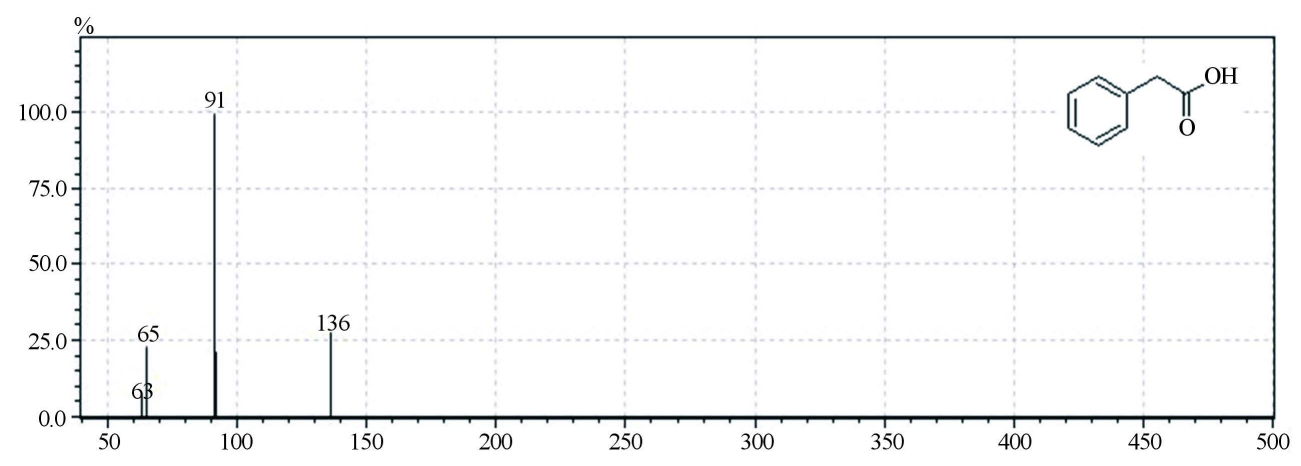

Figure 4. Mass spectrometry analysis of supernatant of $B$. fragilis cultures revealed phenylacetic acid as the major component.

proteic nature. A low-molecular weight extract obtained after passage through a membrane with cut-off of 1000 Dalton could induce the vacuolating phenotype on Vero cells. This active fraction was submitted to gas chromatography and mass spectrometry, which revealed that phenylacetic acid (PA) was the major compound present.

It is clear that organic acids (acetic acid, propionic acid, $n$-butyric acid, succinic acid) are the main products of the anaerobic bacteria metabolism of carbohydrates and proteins in the human colon [20]. In previous studies with B. ovatus, Clostridium perfringens and Fusobacterium varium, the physiological concentrations of acetic acid, propionic acid, $n$-butyric acid, succinic acid and lactic acid were higher than the minimum concentrations capable of inducing cytotoxicity [9]. Whether the mucus layer is lost or the bacteria colonizes the mucus and invades the epithelium, the fact is that the direct exposure to the acids produced by the bacteria to the epithelial cells could determinate a mucosal ulceration. In vivo studies have shown that $n$-butyric acid and succinic acid produced by F. varium or by B. caccae resulted in colonic inflammation ulcerations [20] [21].

Previously PA was described as a uraemic toxin capable of impairing macrophage function via inhibition of iNOS expression, culminating in an inhibitory effect on macrophage-killing [22]. PA also showed an antimicrobial activity against bacteria, as Staphylococcus aures, Escherichia coli and yeast, as Candida albicans [23]. It was recently found that PA and other organic phenolic substances can exert an apoptotic effect on malignous cancer cells in vitro [24].

The production of PA by B. fragilis was described over 30 years ago, and this characteristic was exploited as a useful tool in routine clinical bacteriology [25]. However, knowing the predominance of $B$. fragilis in anaerobic infections, PA could be an important virulence factor, helping the microorganism survive in the competitive environment of the gut through its anti-bactericidal effect. On the other hand, during opportunistic infections caused by $B$. fragilis, PA could avoid macrophage killing through inhibition of the iNOS system. Our work characterized the apoptotic factor expressed by B. fragilis strains as PA, which induces vacuoles on Vero cells, besides an alteration in macrophages morphology, culminating in a death process of both cells. Further investigations will be certainly necessary to define the role of PA in the pathogenesis of infections caused by this microorganism, as well as the role of PA produced by $B$. fragilis in the gastrointestinal tract.

\section{Acknowledgements}

We are especially thankful to Joaquim Santos Filho from Laboratory of Biology of Anaerobes for the excellent technical assistance. This study was supported by grants from the following institutions: CAPES, CNPq, Faperj, Pronex and MCT-CNPq.

\section{References}

[1] DiBaise, J.K., Zhang, H., Crowell, M.D., et al. (2008) Gut Microbiota and Its Possible Relationship with Obesity. Mayo Clinic Proceedings, 83, 460-469. http://dx.doi.org/10.4065/83.4.460

[2] Falk, P.G., Hooper, L.V., Midtvedt, T. and Gordon, J.I. (1998) Creating and Maintaining the Gastrointestinal Ecosystem: What We Know and Need to Know from Gnotobiology. Microbiology and Molecular Biology Reviews, 62, 1157-1170.

[3] Wexler, H.M. (2007) Bacteroides: The Good, the Bad, and the Nitty-Gritty. Clinical Microbiology Reviews, 20, 593- 
621. http://dx.doi.org/10.1128/CMR.00008-07

[4] Sears, C.L. (2009) Enterotoxigenic Bacteroides Fragilis: A Rogue among Symbiotes. Clinical Microbiology Reviews, 22, 349-369. http://dx.doi.org/10.1128/CMR.00053-08

[5] Mayhew, J.W., Onderdonka, B. and Gorbach, S.L. (1975) Effects of Time and Growth Media on Short-Chain Fatty Acid Production by Bacteroides Fragilis. Applied Microbiology, 29, 472-475.

[6] Ginsburg, E., Salomon, D., Sreevalsan, T. and Freese, E. (1973) Growth Inhibition and Morphological Changes Caused by Lipophilic Acids in Mammalian Cells. Proceedings of the National Academy of Sciences of USA, 70, $2457-$ 2461. http://dx.doi.org/10.1073/pnas.70.8.2457

[7] Touw, J.J., van Steenbergen, T.J. and De Graaff, J. (1982) Butyrate: A Cytotoxin for Vero Cells Produced by Bacteroides gingivalis and Bacteroides asaccharolyticus. Antonie van Leeuwenhoek, 48, 315-325. http://dx.doi.org/10.1007/BF00418285

[8] Grenier, D. and Mayrand, D. (1985) Cytotoxic Effects of Culture Supernatants of Oral Bacteria and Various Organic Acids on Vero Cells. Canadian Journal of Microbiology, 31, 302-304. http://dx.doi.org/10.1139/m85-057

[9] Ohkusa, T., Okayasu, I., Ogihara, T., et al. (2003) Induction of Experimental Ulcerative Colitis by Fusobacterium varium Isolated from Colonic Mucosa of Patients with Ulcerative Colitis. Gut, 52, 79-83. http://dx.doi.org/10.1136/gut.52.1.79

[10] Antunes, E.N.F., Ferreira, E.O., Falcao, L.S., et al. (2004) Non-Toxigenic Pattern II and III Bacteroides Fragilis Strains: Coexistence in the Same Host. Research in Microbiology, 155, 522-524. http://dx.doi.org/10.1016/j.resmic.2004.04.008

[11] Rocha, E.R., Owens, G., Smith, C.J. and Carolina, N. (2000) The Redox-Sensitive Transcriptional Activator OxyR Regulates the Peroxide Response Regulon in the Obligate Anaerobe Bacteroides fragilis. Journal of Bacteriology, 182, 5059-5069. http://dx.doi.org/10.1128/jb.182.18.5059-5069.2000

[12] Vieira, J.M.B.D., Vallim, D.C., Ferreira, E.O., et al. (2005) Bacteroides fragilis Interferes with iNOS Activity and Leads to Pore Formation in Macrophage Surface. Biochemical and Biophysical Research Communications, 326, 607613. http://dx.doi.org/10.1016/j.bbrc.2004.11.085

[13] Favre-Bonte, S., Darfeuille-Michaud, A. and Forestier, C. (1995) Aggregative Adherence of Klebsiella pneumoniae to Human Intestine-407 Cells. Infection and Immunity, 63, 1318-1328.

[14] Matsumoto, T., Hayasaki, T., Nishimura, Y., et al. (2006) Butyrate Induces Necrotic Cell Death in Murine Colonic Epithelial Cell MCE301. Biological and Pharmaceutical Bulletin, 29, 2041-2045. http://dx.doi.org/10.1248/bpb.29.2041

[15] Apostolova, N., Blas-Garcia, A. and Esplugues, J.V. (2011) Mitochondria Sentencing about Cellular Life and Death: A Matter of Oxidative Stress. Current Pharmaceutical Design, 17, 4047-4060. http://dx.doi.org/10.2174/138161211798764924

[16] Zimmermann, K.C. and Green, D.R. (2001) How Cells Die: Apoptosis Pathways. Journal of Allergy and Clinical Immunology, 108, S99-S103. http://dx.doi.org/10.1067/mai.2001.117819

[17] Leunk, R.D. (1991) Production of a Cytotoxin by Helicobacter pylori. Reviews of Infectious Diseases, 13, S686-S689. http://dx.doi.org/10.1093/clinids/13.supplement_8.s686

[18] Sakurai, N., Koike, K.A., Irie, Y. and Hayashi, H. (1994) The Rice Culture Filtrate of Bacillus cereus Isolated from Emetic-Type Food Poisoning Causes Mitochondrial Swelling in a HEp-2 Cell. Microbiology and Immunology, 38, 337-343. http://dx.doi.org/10.1111/j.1348-0421.1994.tb01788.x

[19] Figueroa-Arredondo, P., Heuser, J.E., Akopyants, N.S., et al. (2001) Cell Vacuolation Caused by Vibrio cholerae Hemolysin. Infection and Immunity, 69, 1613-1624. http://dx.doi.org/10.1128/IAI.69.3.1613-1624.2001

[20] Sakurazawa, T. and Ohkusa, T. (2005) Cytotoxicity of Organic Acids Produced by Anaerobic Intestinal Bacteria on Cultured Epithelial Cells. Journal of Gastroenterology, 40, 600-609. http://dx.doi.org/10.1007/s00535-005-1594-Z

[21] Ariake, K., Ohkusa, T., Sakurazawa, T., et al. (2000) Roles of Mucosal Bacteria and Succinic Acid in Colitis Caused by Dextran Sulfate Sodium in Mice. Journal of Medical and Dental Sciences, 47, 233-241.

[22] Schmidt, S., Westhoff, T.H., Krauser, P., et al. (2008) The Uraemic Toxin Phenylacetic Acid Impairs Macrophage Function. Nephrology Dialysis Transplantation, 23, 3485-3493. http://dx.doi.org/10.1093/ndt/gfn266

[23] Kim, Y., Cho, J.-Y., Kuk, J.-H., et al. (2004) Identification and Antimicrobial Activity of Phenylacetic Acid Produced by Bacillus licheniformis Isolated from Fermented Soybean, Chungkook-Jang. Current Microbiology, 48, 312-317. http://dx.doi.org/10.1007/s00284-003-4193-3

[24] Kampa, M., Alexaki, V.-I., Notas, G., et al. (2004) Antiproliferative and Apoptotic Effects of Selective Phenolic Acids on T47D human Breast Cancer Cells: Potential Mechanisms of Action. Breast Cancer Research, 6, R63-R74. http://dx.doi.org/10.1186/bcr752

[25] Van Assche, P.F. (1978) Differentiation of Bacteroides fragilis Species by Gas Chromatographic Detection of Phenylacetic Acid. Journal of Clinical Microbiology, 8, 614-615. 